\title{
Kajian Termodinamika Biogas Berbahan Dasar Kotoran Sapi
}

\author{
Luqman Budi Wicaksono dan Ahmad Marzuki* \\ Jurusan Fisika FMIPA -Universitas Sebelas Maret Surakarta \\ Jl. Ir. Sutami No. 36 A Kentingan, Surakarta 57126
}

\begin{abstract}
Intisari
Kajian termodinamika terhadap biogas perlu dilakukan dalam rangka pembuatan biogas cair. Tujuannya adalah untuk memperoleh informasi tentang: kompresibilitas, ekspansivitas, persamaan keadaan, dan titik kritis biogas. Penelitian dilakukan dengan pengambilan data kompressibilitas dan data ekspansivitas. Data kompressibilitas didapat dari perubahan volume ketika biogas diberikan tekanan yang besar. Data ekspansivitas didapat dari perubahan volume ketika biogas diberikan temperatur yang semakin tinggi. Hasil dari eksperimen menunjukan bahwa nilai kompressibilitas diperoleh sebesar $-1,9 \times 10^{-5} \mathrm{~m}^{3} / \mathrm{cmHg}$ dan ekspansivitas diperoleh sebesar 7,3 $\times 10^{-2} \mathrm{~m}^{3} / \mathrm{K}$. Persamaan keadaan biogas diperoleh $\ln \frac{\Delta V}{V}=7,3 \times 10^{-2} \mathrm{~m}^{3} / \mathrm{K}\left(\mathrm{T}-\mathrm{T}_{\circ}\right)+1,9 \times$ $10^{-5} \mathrm{~m}^{3} / \mathrm{cmHg}\left(\mathrm{P}-\mathrm{P}_{\mathrm{o}}\right)$.
\end{abstract}

\begin{abstract}
Thermodynamics study on the process of liquid biogas is needed. The aim is to get information about: compressibility, expansivity, state equation, and biogas critical point. Research was done by taking compressibility and expansivity data. The data of compressibility is gained through the changing of volume when biogas is given a big pressure. The data of expansivity is gained through the changing of volume at higher temperature. The result of the experiment shows the value of compressibility is $-1.9 \times 10^{-5} \mathrm{~m}^{3} / \mathrm{cmHg}$ and the value of expansivity is $7.3 \times 10^{-2} \mathrm{~m}^{3} / \mathrm{K}$. The biogas state equation is $\ln \frac{\Delta V}{V}=7.3 \times 10^{-2} \mathrm{~m}^{3} / \mathrm{K}\left(\mathrm{T}-\mathrm{T}_{\circ}\right)+1.9 \times 10^{-5}$ $\mathrm{m}^{3} / \mathrm{cmHg}\left(\mathrm{P}-\mathrm{P}_{\circ}\right)$.
\end{abstract}

KATA KUNCI: Biogas, state equation, compressibility, expansivity

\section{PENDAHULUAN}

Sumber daya energi mempunyai peran yang sangat penting bagi pembangunan ekonomi nasional. Energi diperlukan untuk pertumbuhan kegiatan industri jasa, perhubungan dan rumah tangga. Dalam jangka panjang, peran energi akan lebih berkembang khususnya guna mendukung pertumbuhan sektor industri dan kegiatan lain yang terkait. Meskipun Indonesia adalah salah satu negara penghasil minyak dan gas, namun berkurangnya cadangan minyak, penghapusan subsidi menyebabkan harga minyak naik dan kualitas lingkungan menurun akibat penggunaan bahan bakar fosil yang berlebihan. Oleh karena itu pemanfaatan sumber energi alternatif yang terbarukan dan ramah lingkungan menjadi pilihan.

Salah satu energi terbarukan adalah biogas, biogas memiliki peluang yang besar dalam pengembangannya. Energi biogas dapat diperoleh dari kotoran sapi. Selain potensi yang besar, pemanfaatan energi biogas dengan digester biogas memiliki banyak keuntungan, yaitu mengurangi efek gas rumah kaca, mengurangi bau yang tidak sedap, dan mencegah penyebaran penyakit. Pemanfaatan limbah dengan cara seperti ini secara ekonomi akan sangat kompetitif seiring naiknya harga

\footnotetext{
*E-MAIL: amarzuki@mipa.uns.ac.id
}

bahan bakar minyak [1]. Teknologi pemanfataan kotoran hewan menjadi energi walaupun sederhana namun mayoritas masyarakat petani/peternak di Indonesia belum bisa memanfaatkannya, hal tersebut disebabkan karena rendahnya SDM peternak/petani, minimnya pelatihan atau penyuluhan kepada masyarakat, rendahnya kepedulian pemerintah daerah untuk serius mengoptimalkan sektor peternakan dan pertanian.

Selama kurun waktu 10 tahun terakhir konsumsi energi di sektor rumah tangga tumbuh rata-rata $1,4 \%$ per tahun. Dalam hal pertumbuhan, jenis energy rumah tangga yang mengalami pertumbuhan cepat adalah LPG, listrik, dan gas bumi yang tumbuh dengan rata-rata tahunan 20\%, 7\%, dan 5\%. Perkembangan konsumsi LPG dan minyak tanah tersebut mengakibatkan terjadinya peningkatan pangsa LPG dalam konsumsi energi rumah tangga dari 1,3\% (1999) menjadi 7,4\% (2009). Permintaan LPG di masa datang diperkirakan terus meningkat dengan terus dilaksanakannya program pengalihan minyak tanah ke LPG di Indonesia saat ini didominasi oleh sektor rumah tangga. Perkembangan pesat konsumsi energi terjadi dalam periode 2005-2009 sebagai hasil pelaksanaan program konversi minyak tanah ke LPG. Pada periode tersebut konsumsi LPG tumbuh rata-rata $31 \%$ per tahun.

Pemanfaatan kotoran ternak sebagai sumber energi biogas sangat efisisen sebagai energi alternatif [2]. Dari sekian banyak kotoran ternak yang terdapat di daerah sentra produksi ternak banyak yang belum dimanfaatkan secara optimal, 


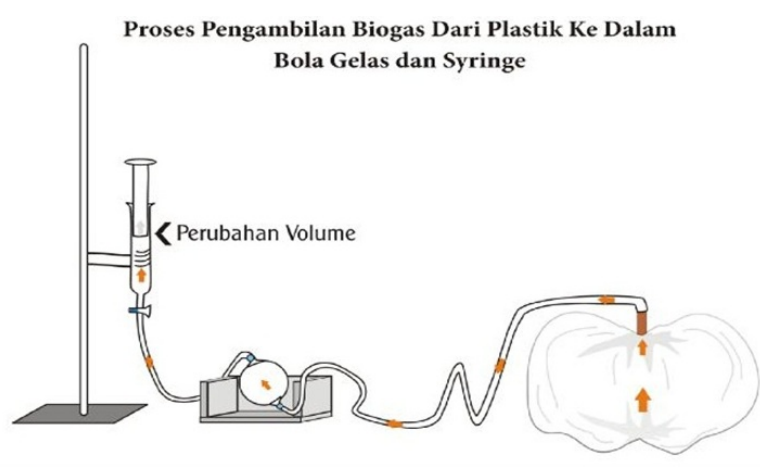

(a)

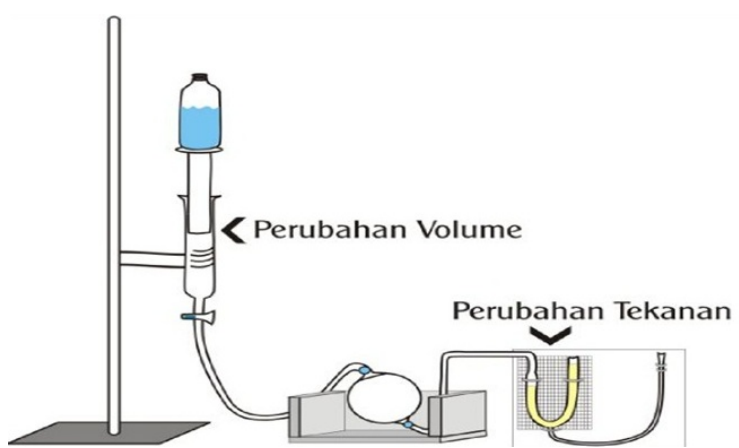

(b)

Gambar 1: (a). pengambilan biogas, (b). setup alat kompressibilitas

sebagian diantaranya terbuang begitu saja, sehingga sering merusak lingkungan yang akibatnya akan menghasilkan bau yang tidak sedap. Satu ekor sapi dewasa dapat menghasilkan 23,59 kg kotoran tiap harinya [3]. Permasalahan yang ada pada biogas, masih didistribusikan secara lokal, karena biogas masih didistribusikan melalui pipa-pipa paralon pemakaianya hanya pada daerah setempat disekitar tempat pembuatan. Biogas juga membutuhkan volume yang besar ketika akan digunakan. Agar dapat didistribusikan seperti LPG yang sekarang ada, maka biogas perlu dibuat cair. Paper ini merupakan bagian dari upaya proses pembuatan biogas menjadi cair.

\section{METODOLOGI}

Kompresibilitas adalah fraksi pengurangan volume persatuan kenaikan perubahan tekanan dalam suatu tekanan seperti diberikan oleh persamaan

$$
K=-\frac{1}{V}\left(\frac{\partial V}{\partial P}\right)_{T}
$$

dengan $\mathrm{K}$ adalah besaran kompressibilitas, $\partial V$ adalah perubahan volum, $\partial P$ adalah perubahan tekanan [4].

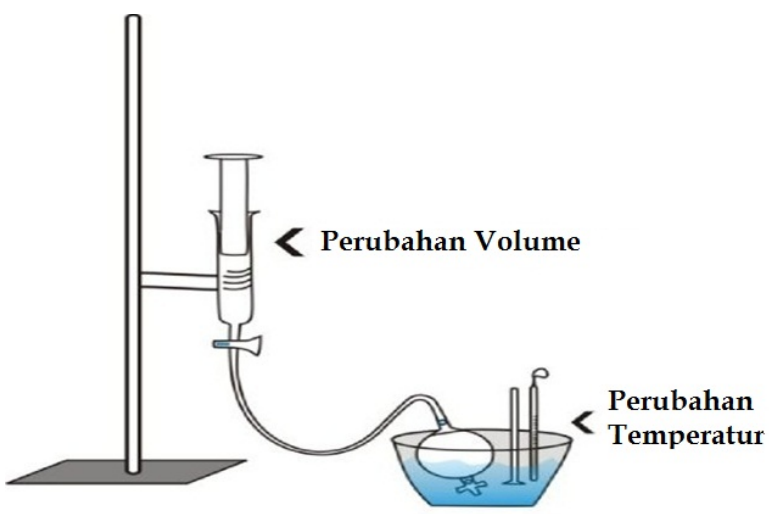

Gambar 2: Setup alat ekspansivitas.
Dalam penelitian ini biogas diambil dari reaktor biogas yang berasal dari kotoran sapi ditampung dengan menggunakan wadah plastik. kemudian disedot menggunakan syringe dan berikutnya dimasukan kedalam bola gelas. Gambar 1(a) dan Gambar 1(b) adalah desain eksperimen kompresibilitas yang digunakan. kompresibilitas dapat diamati dengan memberikan takanan terhadap tabung syringe, ditunjukan oleh Gambar 1(b). Tekanan berasal dari beban yang berupa botol berisi air yang divariasikan massanya. Tabung syringe dilengkapi piston untuk mengetahui perubahan volume yang terjadi, digunakan statif untuk menyangga syringe. Ketika diberikan tekanan maka akan terjadi pemampatan volume, ketika volume bertambah maka akan terjadi perubahan tekanan pada gas. Perubahan tekanan gas dapat diamati melalui pipa U [5]. Terdapat selang yang menghubungkan dari syringe, sphere, dan pipa U. Sphere merupakan bola gelas berisi biogas. Dengan menggunakan Pers.(1), dapat diperoleh nilai kompresibilitasnya [6].

Ketika beban yang massanya diketahui diletakkan pada piston, maka akan terjadi penyusutan volume yang ditunjukan oleh penurunan skala pada syringe sebesar $\Delta V_{1}$, dan yang terjadi pada pipa $U$ akan terjadi kenaikan tekanan ditunjukan kenaikan permukaan air raksa pada salah satu tabung pipa U sebesar $\Delta P_{1}$ [7]. Langkah tersebut dilakukan berulang ulang dengan variasi massa semakin bertambah, artinya biogas akan dikompress dengan tekanan yang semakin besar. Sehingga diperoleh data perubahan volume $(\Delta V)$ dan perubahan tekanan $(\Delta P)$.

Ekspansivitas merupakan fraksi perubahan volume perderajat perubahan temperatur apabila tekanan dijaga konstan. Seperti diberikan oleh persamaan

$$
\beta_{P}=\frac{1}{V}\left(\frac{\partial V}{\partial T}\right)_{P}
$$

dengan $\beta$ adalah besaran ekspansivitas, $\partial V$ adalah perubahan volum, $\partial T$ adalah perubahan temperatur [8].

Dalam penelitian ini bola gelas diletakan ke dalam waterbath. Gambar 2 adalah desain eksperimen ekspansivitas yang digunakan. Ekspansivitas dapat diamati dengan cara menaikan temperatur air, air ditempatkan pada waterbath, air ini berfungsi sebagai pengatur temperatur. Ter- 


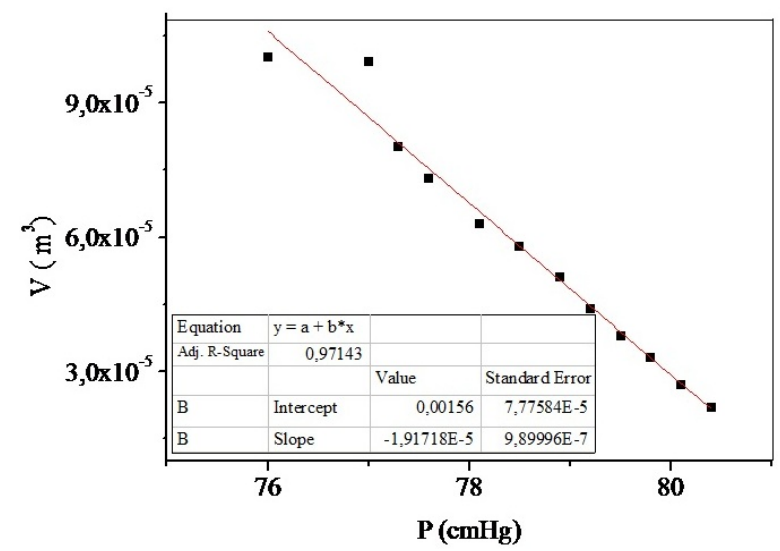

Gambar 3: Grafik hubungan V terhadap P Biogas.

mometer diletakan pada waterbath tersebut berfungsi mengetahui perubahan temperatur air tersebut, ketika temperatur air meningkat volume air juga akan bertambah, peningkatan temperatur menggunakan tambahan air panas, digunakan heater untuk memanaskan air. Pertambahan volume dapat kita amati dengan naiknya piston pada skala syringe [9], dalam hal ini digunakam statif untuk menyangga syringe. maka ketika data pertambahan volume air dan pertambahan temperatur sudah diketahui, nilai ekspansivitas akan dapat diperoleh dengan menggunakan Pers.(2) [6].

Ketika air panas ditambahkan perlahan-lahan sampai terjadi kenaikan temperatur setiap $1{ }^{\circ} \mathrm{C}$, maka akan terjadi pengembangan volume ditunjukan dengan naiknya piston pada skala syringe sebesar $\partial V_{1}$, dan yang terjadi pada temperatur air akan meningkat dengan variasi kenaikan temperatur $\partial T 1^{\circ} \mathrm{C}$. Langkah tersebut dilakukan berulang ulang dengan variasi temperatur semakin bertambah, artinya biogas akan dinaikan temperaturnya dengan temperatur yang semakin besar. Sehingga diperoleh data perubahan volume $(\partial V)$ dan perubahan temparatur $(\partial T)$.

\section{HASIL DAN PEMBAHASAN}

Hasil penelitian yang telah dilaksanakan menghasilkan data, dengan kaitan perubahan volume $(\partial V)$ dan perubahan tekanan $(\partial P)$ pada T tetap dapat dibuat grafik hubungan $\mathrm{P}-\mathrm{V}$ dengan menggunakan persamaan

$$
\Delta V=-K V_{\circ} \Delta P
$$

Gambar 3 memberikan illustrasi hubungan di atas, terlihat bahwa ketika tekanan diperbesar maka volume akan mengecil [10]. Dari Pers.(3) terlihat bahwa kompressibilitas dapat dicari dengan persamaan garis yang terbentuk dari grafik pada Gambar 3. Dengan P sebagai variabel bebas dan V sebagai variabel terikat maka gradien senilai dengan $\mathrm{K} . \mathrm{V}$ 。 sebesar $1,9 \times 10^{-5}$, melalui Pers.(1) dengan membagi gradien dengan $\mathrm{V}_{\circ}\left(10^{-4}\right)$ maka nilai kompressibilitas diperoleh sebesar $1,9 \times 10^{-15} \mathrm{~m}^{3} / \mathrm{cmHg}$.



Gambar 4: Grafik hubungan V terhadap T Biogas.

Berdasar data kaitan perubahan volume $(\partial V)$ dan perubahan temperatur $(\partial T)$ pada $\mathrm{P}$ tetap dapat dibuat grafik hubungan $\mathrm{T}-\mathrm{V}$ yaitu dengan menggunakan persamaan

$$
\Delta V=\beta V_{\circ} \Delta T
$$

Gambar 4 memberikan illustrasi hubungan di atas, terlihat bahwa ketika temperatur dinaikan maka volume akan mengembang [10]. Berdasar Pers.(4) terlihat bahwa ekspansivitas dapat dicari dengan persamaan garis yang terbentuk dari grafik pada Gambar 4. T sebagai variabel bebas dan V sebagai variabel terikat maka gradien senilai dengan $\beta \mathrm{V}_{\text {。 }}$ sebesar 2,7 $\times 10^{-6}$, melalui Pers.(2) dengan membagi gradien dengan $\mathrm{V}_{\circ}\left(3,7 \times 10^{-5}\right)$ maka nilai ekspansivitastas diperoleh sebesar $7,3 \times 10^{-2} \mathrm{~m}^{3} / \mathrm{K}$.

Persamaan keadaan biogas dapat ditentukan melalui persamaan [11]

$$
\Delta V=\left(\frac{\partial V}{\partial T}\right)_{P} d T+\left(\frac{\partial V}{\partial P}\right)_{T} d P
$$

dengan mensubstitusi nilai $\beta$ dan K ke Pers.(5), diperoleh persamaan

$$
\begin{aligned}
\Delta V & =\beta V d T-k V d P \\
\frac{\Delta V}{V} & =\beta d T-K d P \\
\int_{V_{\circ}}^{V} \frac{\Delta V}{V} & =\beta \int_{T_{\circ}}^{T} d T-K \int_{P_{\circ}}^{P} d P
\end{aligned}
$$

Maka persamaan keadaanya menjadi

$$
\ln \frac{\Delta V}{V}=\beta \Delta T-K \Delta P
$$

nilai $\beta=7,31 \times 10^{-2} \mathrm{~m}^{3} / \mathrm{K}, \mathrm{K}=-1,9 \times 10^{-5} \mathrm{~m}^{3} / \mathrm{cmHg}$, maka persamaan keadaan biogas diperoleh

$$
\begin{aligned}
\ln \frac{\Delta V}{V}= & 7,3 \times 10^{-2} \mathrm{~m}^{3} / K\left(T-T_{\circ}\right) \\
& +1,9 \times 10^{-5} \mathrm{~m}^{3} / \mathrm{cmHg}\left(P-P_{\circ}\right)
\end{aligned}
$$


Makna persamaan di atas adalah dV merupakan perubahan volume apabila temperatur dan tekanan diubah atau perubahan total volume $(\partial V / \partial T)_{P} \mathrm{dT}$ merupakan perubahan volume apabila temperatur diubah sebesar $7,3 \times 10^{-2} \mathrm{~m}^{3} / \mathrm{K}$ sedangkan tekanan $(\mathrm{P})$ dijaga tetap. Sedangkan $(\partial V / \partial P)_{T}$ dp adalah perubahan volume apabila tekanan diubah sebesar $-1,9 \times 10^{-5} \mathrm{~m}^{3} / \mathrm{cmHg}$ sedangkan temperatur $(\mathrm{T})$ dijaga tetap [12].

\section{SIMPULAN}

Berdasarkan dari data penelitian, data kompressibilitas didapat dari perubahan volume ketika biogas diberikan tekanan yang besar. Data ekspansivitas didapat dari perubahan volume ketika biogas diberikan temperatur yang semakin tinggi. Hasil dari eksperimen menunjukan bahwa nilai kompressibilitas sebesar $-1,9 \times 10^{-5} \mathrm{~m}^{3} / \mathrm{cmHg}$ dan ekspansivitas sebesar
$7,3 \times 10^{-2} \mathrm{~m}^{3} / \mathrm{K}$. Persamaan keadaan biogas diperoleh $\ln \frac{\Delta V}{V}$ $=7,3 \times 10^{-2} \mathrm{~m}^{3} / \mathrm{K}\left(\mathrm{T}-\mathrm{T}_{\circ}\right)+1,9 \times 10^{-5} \mathrm{~m}^{3} / \mathrm{cmHg}\left(\mathrm{P}-\mathrm{P}_{\circ}\right)$. Pada penelitian lebih lanjut adalah menentukan kondisi kritis biogas agar biogas dapat diubah menjadi cair. Sedangkan untuk penerapan dan aplikasi secara langsung upaya pembuatan biogas cair memerlukan dukungan dari pemerintah dan para peneliti lainya.
[1] D.P Sugi Rahayu, Pemanfaatan Kotoran Ternak Sapi Sebagai Sumber Energi Alternatif Ramah Lingkungan Beserta Aspek Sosio Kulturalnya, Inotek, 150-160 (2009).

[2] A. Pambudi A, Pemanfaatan Biogas sebagai Energi Alternatif, Universitas Sebelas Maret Surakarta, 2008.

[3] T.W. Ana Nurhasanah, Perkembangan Digester Biogas di Indonesia, Pertanian, 1-7 (2009).

[4] F.W. Sears, and G.L Salinger, Thermodynamics Kinetic Theory and Statistical Thermodynamics (Addison-Wesley, Philipines, 1975).

[5] J.H. Dymond, J. Chem. Phys., 60, 969-973 (1974).

[6] A.A Hamid, Kalor dan Thermodinamika (Universitas Negeri Yogyakarta, 2007).

\section{Ucapan Terima Kasih}

Penulis menyampaikan ucapan terima kasih kepada Direktorat Jendaral Pendidikan Tinggi, Departemen Pendidikan dan Kebudayaan Republik Indonesia yang telah memberikan bantuan dana melalui hibah PKM Penelitian serta Bapak Sulis selaku pemilik peternakan yang telah memberikan tempat pembuatan biogas.
[7] K. Gotoh, Nature (London) Phys. Sci., 239, 154-156 (1972).

[8] H.B. Callen, Thermodynamics and an Introduction to Thermostatistics (John Wiley \& Sons, 1989).

[9] M.J. Moran, and H.N. Shapiro, Fundamentals Of Engineering Thermodynamics (2th edition, John Willey and son, 1993).

[10] J. Frenkel, Kinetic Theory of Liquids (Dover, New York, 1955).

[11] S.A Rice, J.P. Boon, and H.T Davis H.T, Comments on the Experimental and Theoritical Study of Transport Phenomena in Simple Liquids (in H.L. Frisch and Z.W Salisbung, Ed, Simple Dense Fluids, Acedemic Press, New York, 1968).

[12] J.O. Hierschielder, C.F. Curtiss, and R.B. Bird, Molecular Theory of Gases and Liquids (Wiley, New York, 1954). 